\title{
A Simple Protocol for the Immunolabelling of Arabidopsis Pollen Tube Membranes and Cell Wall Polymers \\ Marie Dumont ${ }^{1}$, Céline Cataye ${ }^{2}$, Arnaud Lehner ${ }^{1}$, Eric Maréchal ${ }^{2}$, Patrice Lerouge ${ }^{1}$, Denis Falconet $^{2 *}$ and Jean-Claude Mollet ${ }^{1 *}$ \\ ${ }^{1}$ Laboratoire de Glycobiologie et Matrice Extracellulaire Végétale (Glyco-MEV) EA4358, Normandy University, University of Rouen, Institut de Recherche et d'Innovation Biomédicale, Mont-Saint-Aignan, France; 'Laboratoire de Physiologie Cellulaire Végétale, Université Joseph Fourier-Grenoble 1/CEA-iRTSV, Grenoble, France \\ *For correspondence: $\underline{\text { denis.falconet@cea.fr; jean-claude.mollet@univ-rouen.fr }}$
}

[Abstract] The pollen tube, a fast tip-growing cell, is an excellent model to study membrane and cell wall biosynthesis. Here, we describe a simple protocol using an easy to use device to perform immunofluorescence labelling of pollen tube membrane and cell wall. The use of the NucleoSpin column to perform all the steps of the immunolabelling procedure results in obtaining more intact pollen tubes.

\section{Materials and Reagents}

1. Arabidopsis day-0 flowers according to Boavida and McCormick (2007)

Note: Choose the last inflorescence buds opened at the top of the inflorescence stem. The stamen must not be higher than the stigma.

2. Fetal Bovine Serum (FBS) (Sigma-Aldrich, catalog number: F0804)

3. Goat serum (Sigma-Aldrich, catalog number: G9023)

4. Saponin (Sigma-Aldrich, catalog number: S4521)

5. Primary antibody against plant cell wall polysaccharides/glycoproteins (http://www.plantprobes.net or http://www.ccrc.uga.edu/ carbosource) or digalactosyldiacylglycerol (DGDG) prepared in the laboratory using purified DGDG as antigen

6. Secondary antibodies conjugated to Alexa Fluor 488 (Life Technology, catalog number: A-11008) or Fluorescein isothiocyanate (FITC) (Sigma-Aldrich, catalog number: F0382)

7. Arabidopsis pollen germination medium (PGM) (see Recipes)

8. 1x Tris-buffered saline (TBS) (see Recipes)

9. Fixation solution (see Recipes)

10. Calcium- and magnesium-free Dulbecco's phosphate-buffered saline (CMF-DPBS) (see Recipes)

11. Blocking buffer 1 (see Recipes)

12. Blocking buffer 2 (see Recipes) 


\section{Equipment}

1. Pair of tweezers

2. Olympus CK2 inverted microscope

3. Microscope Zeiss AxiObserver Z1

4. Syringe Filter PVDF $33 \mathrm{~mm} 0.2 \mu \mathrm{m}$

5. Microcentrifuge (VWR ${ }^{\mathrm{TM}}$ Galaxy 14D)

6. NucleoSpin ${ }^{\circledR}$ Plasmid Binding Columns (Macherey-Nagel, catalog number: 740588.50), but columns of any other kits (Genejet or PureLink) may be used.

7. Incubators at $22^{\circ} \mathrm{C}$ and $30^{\circ} \mathrm{C}$

8. Parafilm ${ }^{\circledR}$

9. Confocal Microscope TCS-SP2 operating system (Leica) and microscope Leica DMI6000B with a DFC450 C camera with FITC filter (absorption, 485-520 nm; emission, 520-560 nm wavelengths

\section{Procedure}

A. In vitro Arabidopsis pollen tube growth and fixation

Note: See also the protocol available at Li (2011). However we advice to use the conditions detailed in the following protocol (number of flowers, PGM volume, temperature) to enhance the reproducibility.

1. Grow Arabidopsis pollen in vitro according to the method described by Boavida and McCormick (2007).

a. Harvest 40 freshly open Arabidopsis thaliana flowers (morning is the best) using a pair of tweezers.

b. Submerge in $1 \mathrm{ml}$ of PGM in a $1.5 \mathrm{ml}$ Eppendorf tube.

c. Shake the tube vigorously manually and with a vortex for $5 \mathrm{~min}$ to release the pollen grains from the anthers.

d. Check the pollen number density with an inverted microscope.

e. Remove all the flower debris with a pair of tweezers.

f. Spin-down the pollen suspension using the microcentrifuge at 3,200 $x \mathrm{~g}$ for $7 \mathrm{~min}$ (a yellowish pellet should be visible).

g. Remove the supernatant by pipetting.

h. Add $250 \mu \mathrm{l}$ of PGM and resuspend the pellet.

i. Place the tube horizontally in the incubator at $22^{\circ} \mathrm{C}$ in the dark for $6 \mathrm{~h}$.

j. After $6 \mathrm{~h}$, check for pollen germination and pollen tube growth with the inverted microscope (Figure 1). 


\section{bio-protocol}

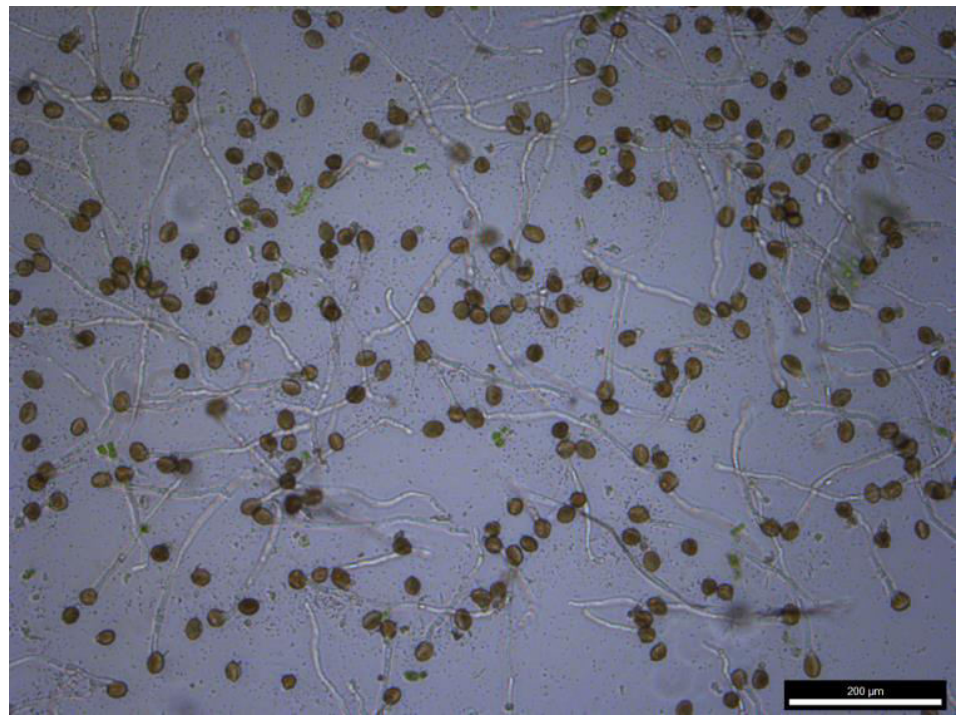

Figure 1. 6 h-old Arabidopsis pollen tubes. Note that the pollen grain density is important to obtain good pollen germination rates.

B. Pollen tube fixation and immunolabelling

Note: The protocol described below is adapted from Botté et al. (2011) and Dumont et al. (2014) for pollen membrane and pollen cell wall labelling respectively. Medium can be removed either by aspiration by connecting the NucleoSpin ${ }^{\circledR}$ Plasmid Binding Column to a vacuum such as a water aspirator (Figure 2) or by centrifugation at $300 \times \mathrm{g}$ for $1 \mathrm{~min}$ in a microcentrifuge. In the aspiration method, the flow-through is discarded and the germinated pollens present on the silica membrane are gently resuspended in the appropriate buffer. Although very similar the two protocols differ with an additional permeabilization step for pollen tube membrane labelling (step B4) and the use of different buffers (Figure 4). Buffers used for the cell wall labelling (Dumont et al., 2014) are written between parentheses.

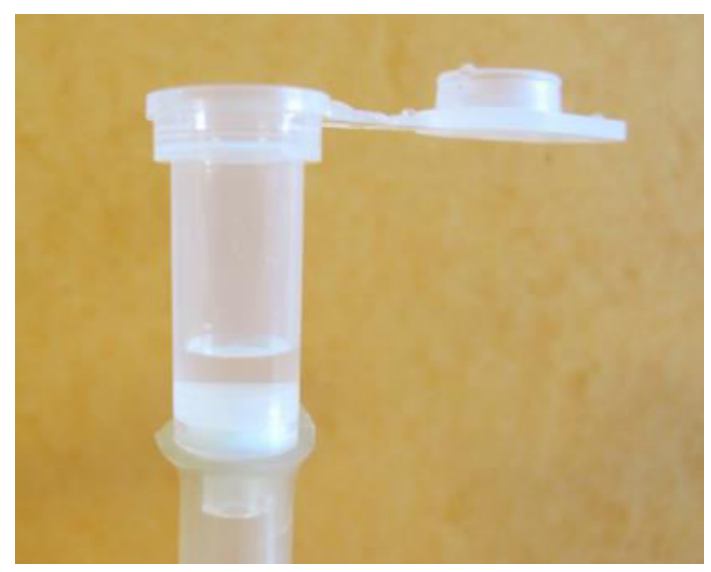

Figure 2. NucleoSpin ${ }^{\circledR}$ Plasmid Binding Columns connected to a hose for aspiration 
1. Pollen tubes in $P G M$ were mixed $(v / v)$ with a fixation medium containing $5 \%$ methanol-free formaldehyde in TBS buffer (or 5\% formaldehyde in the fixation solution). Pollen tubes are incubated overnight at $4{ }^{\circ} \mathrm{C}$ before use (do not store the pollen tubes longer than 1 month).

2. Transfer the pollen tubes solution on a NucleoSpin ${ }^{\circledR}$ Plasmid Binding Column held on a collection tube, under the fumehood.

Note: All transfer and all washing steps described below are performed with a tip cut $0.5 \mathrm{~cm}$ from its extremity to avoid pollen tube damages (such ready to use wide bore pipet tips are available here: http://www.thomassci.com/Supplies/Pipettor-Tips/_/200l-Clear-Wide-Bore-Pipet-Tips? q=Wide\%20Tip\%20Pipet http://catalog2.corning.com/LifeSciences/en-US/Shopping/ProductDetails.aspx?produ ctid=T-205-WB-C\%28Lifesciences\%29\&categoryname=).

3. Remove the medium by aspiration or centrifugation and wash three times with $100 \mu \mathrm{l}$ TBS buffer (or CMF-DPBS, both filtered at $0.22 \mu \mathrm{m}$ using a syringe filter). Pollen tubes are gently resuspended in the buffer by pipetting up and down and the buffer is removed by aspiration/centrifugation.

4. Seal the bottom of the column with parafilm ${ }^{\circledR}$ and add $100 \mu \mathrm{l} 0.002 \%$ saponin in TBS for $15 \mathrm{~min}$ for pollen membrane permeabilization (skip this step and the next one for the cell wall immunolabelling).

5. Remove the medium by aspiration/centrifugation.

6. Seal the bottom of the column with parafilm ${ }^{\circledR}$ and incubate the pollen tubes with $100 \mu \mathrm{l}$ blocking buffer 1 (or blocking buffer 2), freshly prepared, for $1 \mathrm{~h}$.

7. Remove the blocking buffer by aspiration/centrifugation.

8. The cell wall labelling requires three washes with CMF-DPBS as explained in step B3 (Skip this step for the membrane immunolabelling).

9. Seal the bottom of the column and add $50 \mu \mathrm{l}$ of primary antibody 1:10 dilution DGDG-specific rabbit serum in TBS-1\%FBS-0.002\% saponin and incubate $1 \mathrm{~h}$ at room temperature (or for the cell wall labelling: 1:20 primary antibody in CMF-DPBS overnight at $4^{\circ} \mathrm{C}$ ). Negative controls are prepared by omitting the primary antibody.

10. Wash three times with TBS-1\% FBS- $0.002 \%$ saponin (or CMF-DPBS) as explained in step B3.

11. Seal the bottom of the column and add $50 \mu \mathrm{l}$ 1:500 dilution Alexa secondary antibody in TBS-1\%FBS- $0.002 \%$ saponin and incubate $1 \mathrm{~h}$ at room temperature (or for the cell wall labelling: FITC-coupled secondary antibody 1:50 dilution in CMF-DPBS for $2 \mathrm{~h}$ at $\left.30^{\circ} \mathrm{C}\right)$.

Note: From this step, keep the tubes in the dark in aluminum foil.

12. Wash four times in TBS-1\% FBS- $0.002 \%$ saponin and a final wash with TBS (or five times with CMF-DPBS) as explained in step B3. 


\section{biö-protocol}

13. In order to recover the pollen tubes, resuspend them by adding at the top of the column $100 \mu$ of TBS (or water) and by pipetting up and down several times with an enlarged tip and transfer the solution which contains the pollen tubes on a microscope slide with a cover slip. Figure 3 shows the confocal images showing the results of immunofluorescence labelling of Arabidopsis pollen tubes with anti-DGDG. Figure 4 gives an overview of the method for the membrane or cell wall immunolabelling of pollen tubes.

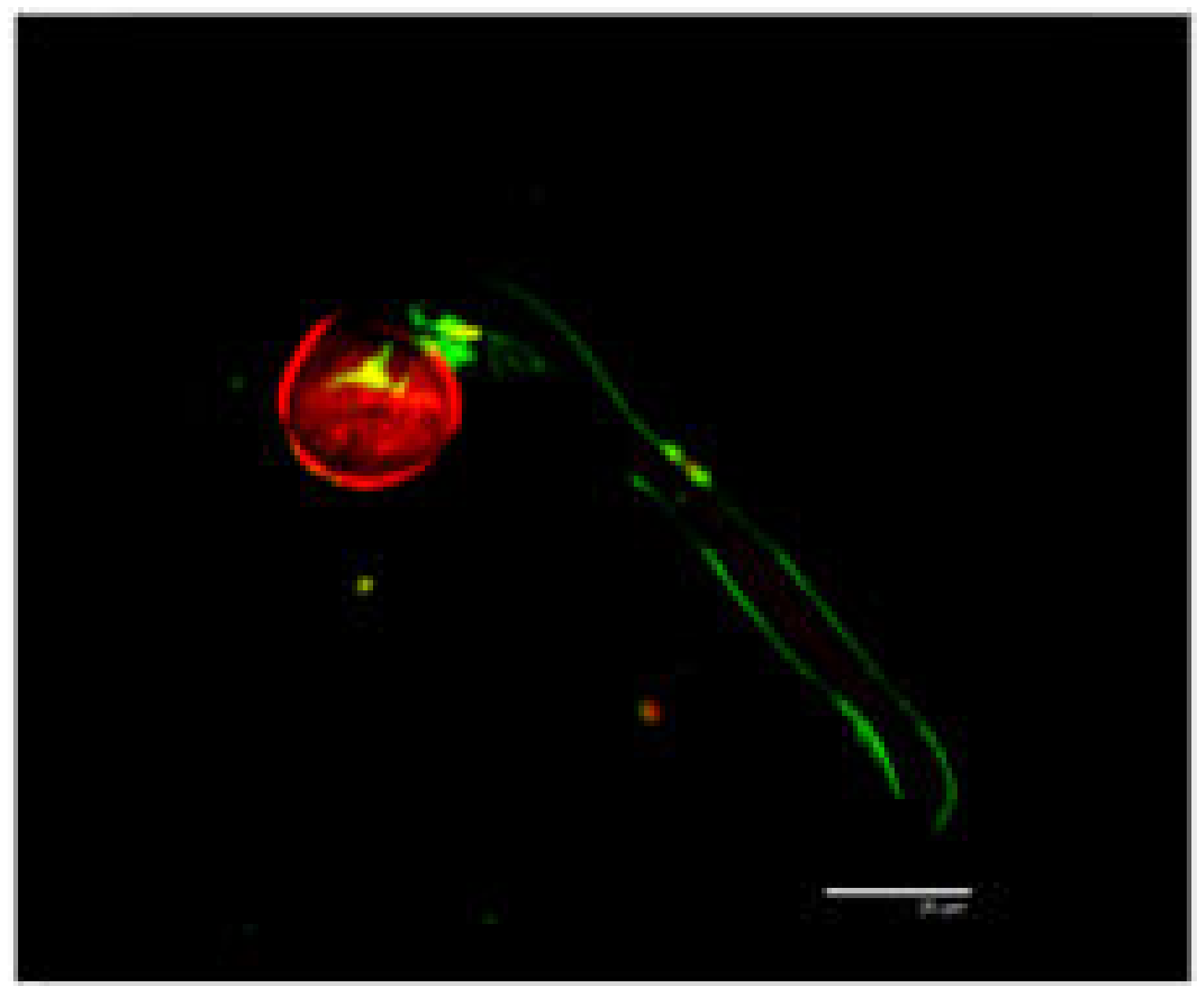

Figure 3. Arabidopsis pollen grains were germinated for $6 \mathrm{~h}$, pollen tubes were fixed and the pollen tube membrane immunolabelled with anti-DGDG antibodies. Alexa 488 was excited using the $488 \mathrm{~nm}$ line of an argon laser and fluorescence was collected between $500-539 \mathrm{~nm}$. Superposition of control red autofluorescence induced by excitation at $543 \mathrm{~nm}$ laser is also shown. 


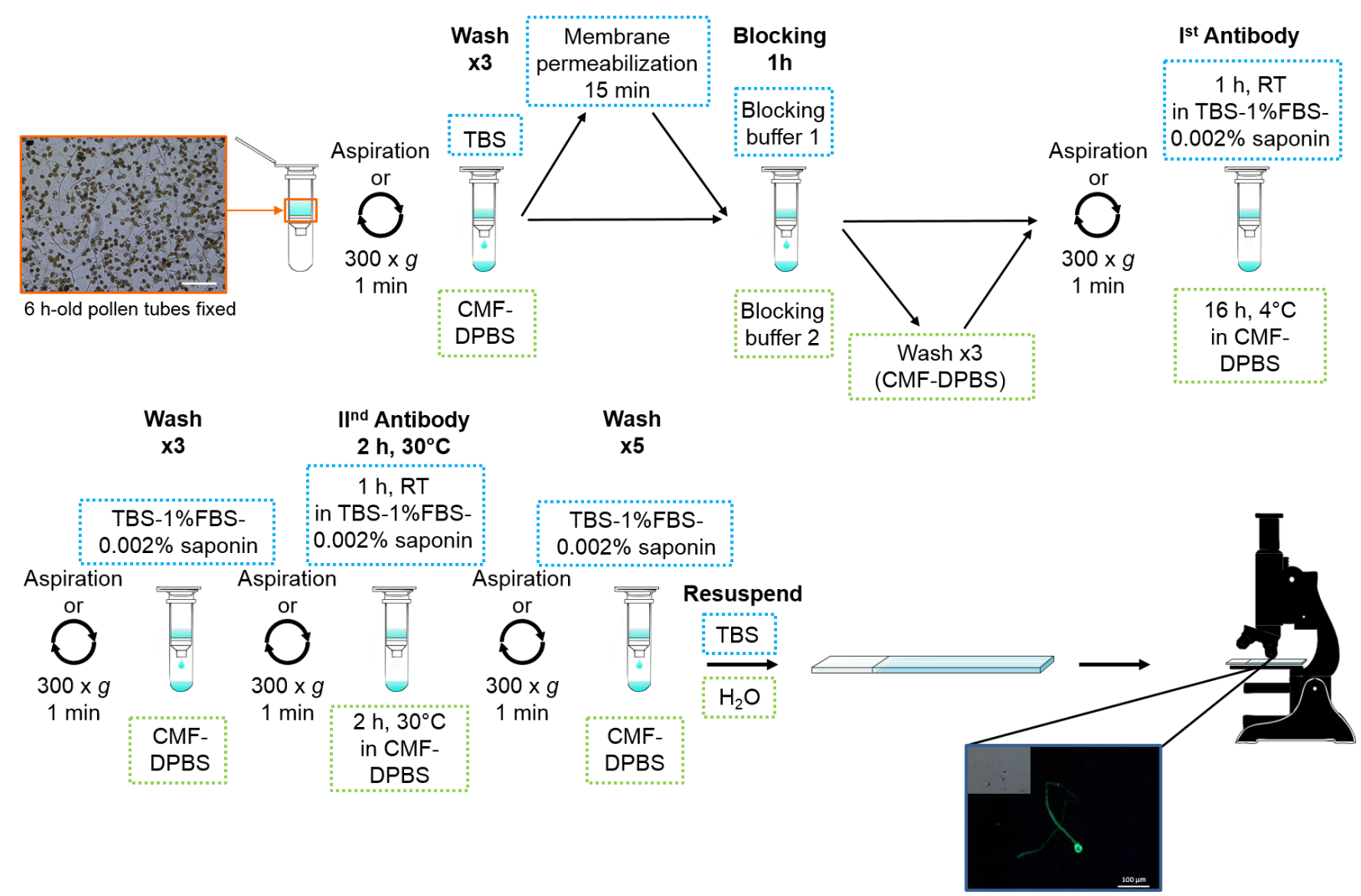

Figure 4. Schematic representation of the sample preparation for Arabidopsis pollen tubes plasma membrane and cell wall immunolabelling. Green dashed box indicates special step or buffer for plasma membrane labelling whereas blue dashed box points out the steps for the cell wall labelling. The picture at the bottom of the image shows a pollen tube labelled with an anti-rhamnogalacturonan-Il (a pectic motif) antibody developed by Matoh et al. (1998) using a microscope Leica DMI6000B equipped with a DFC450 C camera (FITC filter: absorption, 485-520 nm; emission, 520-560 nm wavelengths).

\section{Recipes}

1. Arabidopsis Pollen Germination Medium (PGM)

$5 \mathrm{mM} \mathrm{CaCl}_{2}$

$0.01 \% \mathrm{H}_{3} \mathrm{BO}_{3}$

$1 \mathrm{mM} \mathrm{MgSO}_{4}$

$5 \mathrm{mM} \mathrm{KCl}$

$10 \%(w / v)$ sucrose

$\mathrm{pH} 7.5$

2. $1 x$ Tris-buffered saline (TBS)

$50 \mathrm{mM}$ Tris- $\mathrm{HCl}$

$150 \mathrm{mM} \mathrm{NaCl}$ 
$\mathrm{pH} 7.4$

3. Fixation solution

100 mM PIPES buffer $\mathrm{pH} 6.9$

$4 \mathrm{mM} \mathrm{MgSO}_{4} 7 \mathrm{H}_{2} \mathrm{O}$

4 mM EGTA

$10 \%(\mathrm{w} / \mathrm{v})$ sucrose

$5 \%(\mathrm{v} / \mathrm{v})$ paraformaldehyde

4. Calcium- and magnesium-free Dulbecco's phosphate-buffered saline (CMF-DPBS)

$137 \mathrm{mM} \mathrm{NaCl}$

$2.7 \mathrm{mM} \mathrm{KCl}$

$7 \mathrm{mM} \mathrm{Na}_{2} \mathrm{HPO}_{4} 7 \mathrm{H}_{2} \mathrm{O}$

$1.5 \mathrm{mM} \mathrm{KH}_{2} \mathrm{PO}_{4}$

$\mathrm{pH} 7.2$

5. Blocking buffer 1

1x TBS

$5 \%(w / v)$ FBS

$5 \%(\mathrm{w} / \mathrm{v})$ goat serum

$0.002 \%$ Saponin

6. Blocking buffer 2

$137 \mathrm{mM} \mathrm{NaCl}$

$2.7 \mathrm{mM} \mathrm{KCl}$

$7 \mathrm{mM} \mathrm{Na}_{2} \mathrm{HPO}_{4} \cdot 7 \mathrm{H}_{2} \mathrm{O}$

$1.5 \mathrm{mM} \mathrm{KH}_{2} \mathrm{PO}_{4}$

$\mathrm{pH} 7.2$

$3 \%$ fat-free milk

Note: It is better to filter at $0.22 \mu \mathrm{m}$ using a syringe filter all the washing solutions.

\section{Acknowledgments}

Original versions of the protocols were described in Dardelle et al. (2010), Botté et al. (2011) and Dumont et al. (2014). This work was supported by the University of Rouen, the region Haute Normandie, and the "Trans Channel Wallnet" project that was selected by the INTERREG IVA program France (Channel) - England European cross-border cooperation program, which is co-financed by the European Regional Development Funds (ERDF). The work performed at LPCV (Grenoble) was supported by the Agence Nationale de la Recherche (ANR-10-BLAN-1524, ReGal; ANR BioAdapt Reglisse). 


\section{References}

1. Boavida, L.C. and McCormick, S. (2007). TECHNICAL ADVANCE: Temperature as a determinant factor for increased and reproducible in vitro pollen germination in Arabidopsis thaliana. Plant J 52(3): 570-582.

2. Botté, C.Y., Deligny, M., Roccia, A., Bonneau, A.L., Saïdani, N., Hardré, H., Aci, S., Yamaryo-Botté, Y., Jouhet, J., Dubots, E., Loizeau, K., Bastien, O., Bréhélin, L., Joyard, J., Cintrat, J. C., Falconet, D., Block, M. A., Rousseau, B., Lopez, R., and Maréchal, E. (2011). Chemical inhibitors of monogalactosyldiacylglycerol synthases in Arabidopsis thaliana. Nat Chem Biol 7(11): 834-842.

3. Dardelle, F., Lehner, A., Ramdani, Y., Bardor, M., Lerouge, P., Driouich, A. and Mollet, J.C. (2010). Biochemical and immunocytological characterizations of Arabidopsis pollen tube cell wall. Plant Physiol 153(4): 1563-1576.

4. Dumont, M., Lehner, A., Bouton, S., Kiefer-Meyer, M. vC., Voxeur, A., Pelloux, J., Lerouge, P., and Mollet, J.C. (2014). The cell wall pectic polymer rhamnogalacturonan-II is required for proper pollen tube elongation: implications of a putative sialyltransferase-like protein. Ann Bot 114(6): 1177-1188.

5. PlantProbes: http://www.plantprobes.net

6. CarboSource Services: http://www.ccrc.uga.edu/ carbosource

7. Li, X. (2011). Arabidopsis pollen tube germination. Bio-protocol Bio101: e73.

8. Matoh, T., Takasaki, M., Takabe, K., and Kobayashi, M. (1998) Immunocytochemistry of rhamnogalacturonan II in cell walls of higher plants. Plant Cell Physio/ 39: 483-491. 